ISSN 0103-9954

\title{
CONCENTRAÇÃO E REDISTRIBUIÇÃO DE NUTRIENTES NAS FOLHAS E NO FOLHEDO EM UM POVOAMENTO DE Acacia mearnsii De Wild. NO RIO GRANDE DO SUL
}

\section{CONCENTRATION AND REDISTRIBUTION OF NUTRIENTS IN THE LEAVES AND IN THE LITTER OF Acacia mearnsii De Wild. STAND AT IN RIO GRANDE DO SUL STATE}

\author{
Marcos Vinícius Winckler Caldeira ${ }^{1}$ Mauro Valdir Schumacher ${ }^{2} \quad$ Josani Carbonera Pereira $^{3}$ \\ Jocelaine Bolzan Della-Flora ${ }^{4} \quad$ Elias Moreira dos Santos ${ }^{5}$
}

\begin{abstract}
RESUMO
Este trabalho teve por objetivo estudar as concentrações e a redistribuição de nutrientes minerais nas folhas recém maduras e no folhedo em um povoamento de Acacia mearnsii De Wild, com 3 anos de idade, plantado em solos de baixa fertilidade, no Estado do Rio Grande do Sul. Dentre os elementos minerais analisados o $\mathrm{N}$ foi o que teve maior concentração tanto nas folhas récem maduras como no folhedo. O fósforo e o potássio foram os nutrientes que mais retranslocaram. No entanto, o cálcio foi o elemento que teve uma menor retranslocação.
\end{abstract}

Palavras-chave: Nutrientes, ciclagem, redistribuição, Acacia mearnsii De Wild.

\begin{abstract}
This work aimed to study the concentration and the redistribution of mineral nutrients in the newly mature leaves and in the litter, in a three years old Acacia mearnsii De Wild. forest, planted in soils with low fertility in Rio Grande do Sul State. Among the mineral elements analysed nitrogen had higher concentration in the newly mature leaves as well in the litter. Phosphorus and potassium were the nutrients more retranslocated. However, calcium was the element that presents had the smaller retranslocation.
\end{abstract}

Key words: Nutrients, cycling, redistribution, Acacia mearnsii De Wild..

\section{INTRODUÇÃO}

No estudos de processo de transferência de nutrientes entre os componentes de um

1. Engenheiro Florestal, Acadêmico de Doutorado do Curso de Pós-Graduação em Engenharia Florestal. Escola de Florestas. Universidade Federal do Paraná. Caixa Postal 2959. CEP: 80035-010. Curitiba. PR.

2. Engenheiro Florestal, Dr., Professor Adjunto do Departamento de Ciências Florestais. Centro de Ciências Rurais. Universidade Federal de Santa Maria. CEP: 97105-900. Santa Maria. RS.

3. Engenheira Florestal, DAER/EMA. Av. Borges de Medeiros, 1555/15 andar. CEP: 90110-150. Porto Alegre. RS.

4. Engenheira Florestal, mestranda pelo Programa de Pós-Graduação em Engenharia Florestal. Centro de Ciências Rurais. Universidade Federal de Santa Maria. CEP: 97105-900. Santa Maria. RS.

5. Engenheiro Florestal, Empresa Florestal AGROSETA S.A. Supervisor de Pesquisa e Desenvolvimento. Rua Rodolfo Schimeling, 163. CEP: 95860-000. Taquari. RS. 
ecossistema florestal é conveniente a adoção da classificação de Switzer \& Nelson apud DANTAS (1994), que definem o ecossistema em termos de ciclo geoquímico, ciclo biogeoquímico e ciclo bioquímico.

A senescência e a abcissão das folhas são mecanismos através dos quais as árvores reciclam os nutrientes tanto através do ciclo bioquímico, como biogeoquímico. (VETTORAZZO et al. 1993).

O ciclo bioquímico envolve a redistribuição de nutrientes de tecidos velhos para tecidos novos da planta, ou seja, diz respeito à transferência de nutrientes no próprio interior da biomassa.

A variação sazonal na composição mineral dos diferentes tecidos das árvores é um fenômeno assinalado por diversos pesquisadores dentre os quais se destacam Duvigneaud \& Denaeyer-Desmet apud POGGIANI (1992), os quais observaram, em florestas decíduas, que a concentração de cálcio e do potássio no suco xilemático das árvores varia durante o ciclo vegetativo, havendo uma translocação geral dos nutrientes dos órgãos senescentes para as regiões em fase ativa de crescimento.

A concentração de nutrientes nas folhas das árvores é influenciada por diversos fatores, como as condições do sítio, a idade das folhas, posição das folhas na copa e a época do ano (VAN DEN DRIESSCHE, 1974).

Em solos de baixa fertilidade onde a demanda por nutrientes na planta é elevada, a ciclagem interna é bem mais acentuada.

Segundo RESENDE et al. (1992), existem aproximadamente 1200 espécies de gênero Acacia. Dentre estes gêneros destaca-se a Acácia-negra (Acacia mearnsii De Wild) que constitui-se numa importante espécie florestal ao Rio Grande do Sul, cuja área atual plantada é superior a 160.000 ha, e distribuída principalmente em minifúndios.

Apesar da grande importância da Acácia-negra há carência de informações básicas em quase todos os aspectos de sua cultura e utilização.

Este trabalho teve por objetivo avaliar a redistribuição de nutrientes entre as folhas recém maduras das árvores e as folhas senescentes de Acacia mearnsii De Wild..

\section{MATERIAL E MÉTODOS}

O povoamento de Acacia mearnsii utilizado localiza-se no município de Butiá/ RS, situado entre às coordenadas geográficas de $30^{\circ} 07^{\prime} 12^{\prime \prime}$ de Latitude Sul e 51 57' 45" de Longitude Oeste, numa altitude de $35 \mathrm{~m}$.

$\mathrm{Na}$ região, segundo a classificação de Köppen, o clima é do tipo Cfa caracterizado como subtropical, em que a temperatura do mês mais frio oscila entre $-3^{\circ} \mathrm{C}$ e $18^{\circ} \mathrm{C}$ e a temperatura média do mês mais quente ultrapassa $23^{\circ} \mathrm{C}$. A precipitação pluviométrica anual é em torno de $1.600 \mathrm{~mm}$, a temperatura média anual $18,2^{\circ} \mathrm{C}$ e a insolação 2.300 horas (MORENO, 1961).

Segundo EMBRAPA (1973), os solos da região em estudo pertence a Unidade de 
Mapeamento São Jerônimo, classificado como Laterítico Bruno Avermelhado Distrófico, textura argilosa, relevo ondulado e substrato granito. Normalmente, estes solos são fortemente ácidos, com saturação e soma de bases baixa e com teores baixos de matéria-orgânica.

O povoamento de Acacia mearnsii foi plantado em agosto de 1994, com espaçamento de 1,7 $\mathrm{m} \times 3,0 \mathrm{~m}$. No momento da instalação do experimento o povoamento encontrava-se com 3 anos de idade. Em uma área com condições homogêneas de sítio foram demarcadas 2 parcelas em no formato retangular com $18 \mathrm{~m} \times 24 \mathrm{~m}\left(432 \mathrm{~m}^{2}\right)$.

Após 40 dias realizou-se a coleta das folhas tendo sido amostradas 5 árvores para cada parcela. Nestas árvores selecionadas aleatoriamente foram coletadas folhas recém-maduras provenientes de ramos localizados em pontos ortogonais da parte intermediária das copas. Também, foram amostradas folhas retiradas do folhedo presente em 10 bandejas coletoras com $1 \mathrm{~m}^{2}$, distribuídas ao acaso sob a copa das árvores.

As folhas da copa e do folhedo constituíram-se em 4 amostras compostas. Em seguida, as amostras foram colocadas para secar em estufa à temperatura de $70^{\circ}$ a $85^{\circ} \mathrm{C}$, até atingir peso constante.

Para a determinação da concentração dos macronutrientes (N, P, K, Ca e Mg) nas folhas récem maduras e no folhedo utilizou-se a metodologia proposta por TEDESCO et al. (1985). As determinações foram realizadas no Laboratório de Solos da Universidade Federal do Rio Grande do Sul.

A comparação entre a concentração de nutrientes no folhedo e nas folhas recém maduras da copa e a estimativa de redistribuição de nutrientes foram baseadas no trabalho realizado por ATTIWILL et al. (1978). A expressão utilizada para quantificar a redistribuição de nutrientes foi:

Redistribuição $=$ Concentração no folhedo - Concentração nas folhas $/$ Concentração nas folhas $\times 100$

\section{RESULTADOS E DISCUSSÃO}

As concentrações dos nutrientes nas folhas recém maduras e no folhedo, bem como a redistribuição no povoamento de Acácia-negra podem ser observados na Tabela 1.

Verifica-se que o nitrogênio foi o elemento mais abundante tanto nas folhas recém maduras como no folhedo, entretanto, não foi o mais redistribuído, demosntrando desta maneira a sua baixa capacidade de retranslocação na Acácia-negra.

Os valores da Tabela 1, evidenciam que as concentrações de nutrientes nas folhas récem maduras são superiores na sua totalidade comparadas às concentrações de nutrientes no folhedo. Isso confirma que as concentrações de nutrientes móveis nas folhas senescentes diminui devido sua transferência para as partes em crescimento das árvores. 
TABELA 1: Concentração média de nutrientes nas folhas récem maduras e no folhedo de Acácianegra e estimativa da redistribuição de nutrientes.

\begin{tabular}{c|c|c|c}
\hline Povoamento Comercial & Folhas (\%) & Folhedo (\%) & Redistribuição (\%) \\
\hline N & 2,41 & 1,64 & $-31,95$ \\
P & 0,09 & 0,04 & $-55,55$ \\
K & 0,82 & 0,38 & $-53,66$ \\
$\mathrm{Ca}$ & 0,69 & 0,52 & $-24,64$ \\
$\mathrm{Mg}$ & 0,25 & 0,17 & $-32,00$ \\
\hline
\end{tabular}

Para a concentração de nutrientes nas folhas recém maduras, observa-se a seguinte ordem: $\mathrm{N}$ $>\mathrm{K}>\mathrm{Ca}>\mathrm{Mg}>\mathrm{P}$. VETTORAZZO et al. (1993), verificaram essa mesma tendência para $E$. grandis e E. camaldulensis. Já para E. torelliana essa tendência não foi observada.

A Tabela 1 mostra a redistribuição, em percentagem, dos nutrientes no folhedo. Aproximadamente $32 \%$ de $\mathrm{N} ; 56 \%$ de $\mathrm{P} ; 54 \%$ de $\mathrm{K} ; 25 \%$ de $\mathrm{Ca}$ e $32 \%$ de $\mathrm{Mg}$ foram distribuídos para outras partes da planta antes da abscisão foliar. Desta maneira, pode se dizer que grande parte das necessidades nutricionais desta espécie são supridas pelo ciclo bioquímico.

No caso da Acácia-negra por ser tratar de leguminosa, fixa o nitrogênio atmosférico e mediante a matéria orgânica aumenta os teores deste no solo.

Dos elementos analisados o $\mathrm{P}$ e o $\mathrm{K}$ foram os elementos que mais redistribuíram. A ordem de redistribuição foi $\mathrm{P}>\mathrm{K}>\mathrm{Mg}>\mathrm{N}>\mathrm{Ca}$ (Tabela 1). De acordo com MENGEL \& KIRKBY (1978), o N, P, K e Mg são os elementos de maior mobilidade dentro das plantas.

$\mathrm{O}$ fato do Ca ser o elemento menos redistribuído explica-se por este ser de baixa mobilidade. Para ATTIWILL et al. (1978), como o Ca está associado à lignificação das paredes celulares, este elemento não é redistribuído para as partes novas da planta.

Segundo ASHTON (1975 e 1976); ATTIWILL et al. (1978), quando as folhas de eucalipto se tornam senescentes a retranslocação de nutrientes com o $\mathrm{N}$ e $\mathrm{P}$ podem ultrapassar a $50 \%$ do conteúdo total. Esta afirmação foi comprovada por VETTORAZZO et al. (1993), em trabalho realizado com $E$. grandis.

Nas folhas maduras da copa, onde a atividade fisiológica é mais intensa, foram encontrados os maiores valores para todos os elementos, tanto móveis como imóveis (Tabela 1).

AMARAL et al. (1996), encontraram valores para Dalbergia nigra que evidenciou somente os elementos mais móveis tiveram valores mais altos na parte superior da copa, enquanto os elementos de menor mobilidade, como o $\mathrm{Ca}$, acumularam nas partes inferiores da copa. Por outro lado, na Myroxylon peruiferum, o comportamento dos elementos móveis e poucos móveis foi o oposto da tendência observada na Dalbergia nigra. 


\section{CONCLUSÕES}

De acordo com os resultados deste trabalho, pôde-se concluir que:

$\mathrm{O}$ gradiente de concentração dos nutrientes nas folhas récem maduras e no folhedo foram respectivamente, $\mathrm{N}>\mathrm{K}>\mathrm{Ca}>\mathrm{Mg}>\mathrm{P} ; \mathrm{N}>\mathrm{Ca}>\mathrm{K}>\mathrm{Mg}>\mathrm{P}$.

$>\mathrm{Ca}$.

$\mathrm{O}$ gradiente de redistribuição dos nutrientes foram respectivamente, $\mathrm{P}>\mathrm{K}>\mathrm{Mg}>\mathrm{N}$

\section{AGRADECIMENTOS}

Os autores desejam expressar os seus agradecimentos a Empresa Florestal AGROSETA S.A, por possibilitar a realização desta pesquisa.

\section{REFERÊNCIAS BIBLIOGRÁFICAS}

AMARAL, C.S., GRAÇA, P.M.L.A, BRITO, M.M.P.B., JUNIOR, C.H.A., CAMPOS, D.C. Comparação entre a concentração de nutrientes das folhas e do folhedo do Jacarandá-da-Bahia (Dalbergia nigra) e da Cabreúva (Myroxylon peruiferum). In: SOLO SUELO - CONGRESSO LATINO AMERICANO DE CIÊNCIA DO SOLO, 13, 1996, Águas de Lindóia. Resumos Expandidos... Águas de Lindóias: SLCS: ESALQ/USP: CEA-ESALQ/USP:SBM, 1996. Publicação apresentada em CD-ROM.

ASHTON, D.H. Phosphorus in forest ecosystems at Beenak Victoria. Journal of Ecology, Oxford, v.64, p.171-186, 1976.

ASHTON, D.H. Studies of litter in Eucalyptus regnans forests. Australian Journal of Botany, Melbourne. v. 23, p. 413-433, 1975.

ATTIWILL, P.M., GUTHRIE, H.B., LEUNING, R. Nutrient cycling in a Eucalyptus obliqua (L'Herit) forest. I. Litter production and nutrient return. Australian Journal of Botany, Melbourne, v.261, p.79-91, 1978.

DANTAS, S.V. Precipitação e ciclagem de nutrientes em ecossistemas florestais. Floresta e Ambiente, Rio de Janeiro, ano 1 p.117-122. 1994.

EMPRESA BRASILEIRA DE PESQUISA AGROPECUÁRIA. Levantamento de reconhecimento dos solos do Estado do Rio Grande do Sul. Recife, 1973. (Boletim Técnico, $30)$.

MENGEL, K.; KIRKBY, E.A. Principles of plant nutrition. Bem, International Potash Institute, 1978. 593p.

MORENO, J.A. Clima do Rio Grande do Sul. Secretaria da Agricultura. Porto Alegre, 1961. 
POGGIANI, F. Alterações dos ciclos biogeoquímicos em florestas. In:CONGRESSO NACIONAL SOBRE ESSÊNCIAS NATIVAS, 2, 1992. Anais... São Paulo, p.734-739; 1992.

RESENDE, M.D.V. de, HIGA, A.R., HELLER, J.B., STEIN, P.P. Parâmetros genéticos e interação genótipo $\mathrm{x}$ ambiente em teste de procedências e progênies de acácia-negra (Acacia mearnsii DE WILD.) Boletim de Pesquisa Florestal, Colombo, n 24/25. p.55-65, jan/dez, 1992.

TEDESCO, M.J., VOLKWEISS, S.J., BOHNEN, H. Análise de solos, plantas e outros materiais. Porto Alegre: Departamento de Solos/Faculdade de Agronomia - UFRGS (Boletim Técnico, 5). $188 \mathrm{p}, 1985$.

VAN DEN DRIESSCHE, R. Prediction of mineral status of trees by foliar analysis. The Botanical Review, New York, v.40, p.347-394, 1974.

VETTORAZZO, S.C., POGGIANI, F., SCHUMACHER, M.V. Concentração e redistribuição de nutrientes nas folhas e no folhedo de três espécies de Eucalyptus. In: CONGRESSO FLORESTAL BRASILEIRO, 7, CONGRESSO FLORESTAL PANAMERICANO1, 1993. Curitiba. Anais... Curitiba, v.2, p.231-234, 1993. 